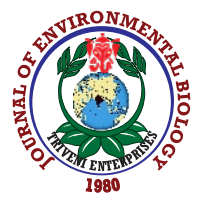

\title{
Fishery and biological traits of obtuse barracuda Sphyraena obtusata (Cuvier, 1829) off south-west coast of India
}

\author{
K.M. Rajesh', P. Rohit ${ }^{1 *}$ and E.M. Abdussamad ${ }^{2}$ \\ 'ICAR-Central Marine Fisheries Research Institute, Mangalore Research Centre, Mangalore-575 001, India \\ ${ }^{2}$ ICAR-Central Marine Fisheries Research Institute, Kochi-682 018, India \\ *Corresponding Author Email : rohitprathi@yahoo.co.in
}

\section{Abstract}

Aim: The present study was conducted to investigate the fishery, diet composition and reproductive aspects of obtuse barracuda landed in Karnataka, south-west coast of India.

Methodology: Feeding and reproductive traits of 1229 samples ( 638 males and 591 females) of $S$. obtusata was studied for a period of five years. The index of relative importance (IRI) was determined for each diet component in the stomach. Reproductive aspects such as maturity stages, gonadosomatic index and fecundity were investigated.

Results: The most predominant prey item in terms of frequency of occurrence (93.1\%), number $(91.4 \%)$, weight (93.2\%), IRI (3615.5) and also \% IRI (98.5\%) was fishes. Crustaceans and cephalopods were noticed less frequently and were represented by shrimps and Loligo $\mathrm{sp}$. The estimated length at first maturity for male and female fishes was 20.5 and $21.3 \mathrm{~cm}$, respectively. Higher GSI values were observed during post monsoon (October-November) followed by summer pre monsoon (April-May) season in both males and females, indicating two peak spawning periods.

Interpretation: The comprehensive study on major biological characteristics of Sphyraena obtusata could be useful for developing appropriate management strategies for conservation and judicious exploitation of this commercially important resource.

Key words: Barracuda, Fecundity, Gonadosomatic index, Sphyraena obtusata

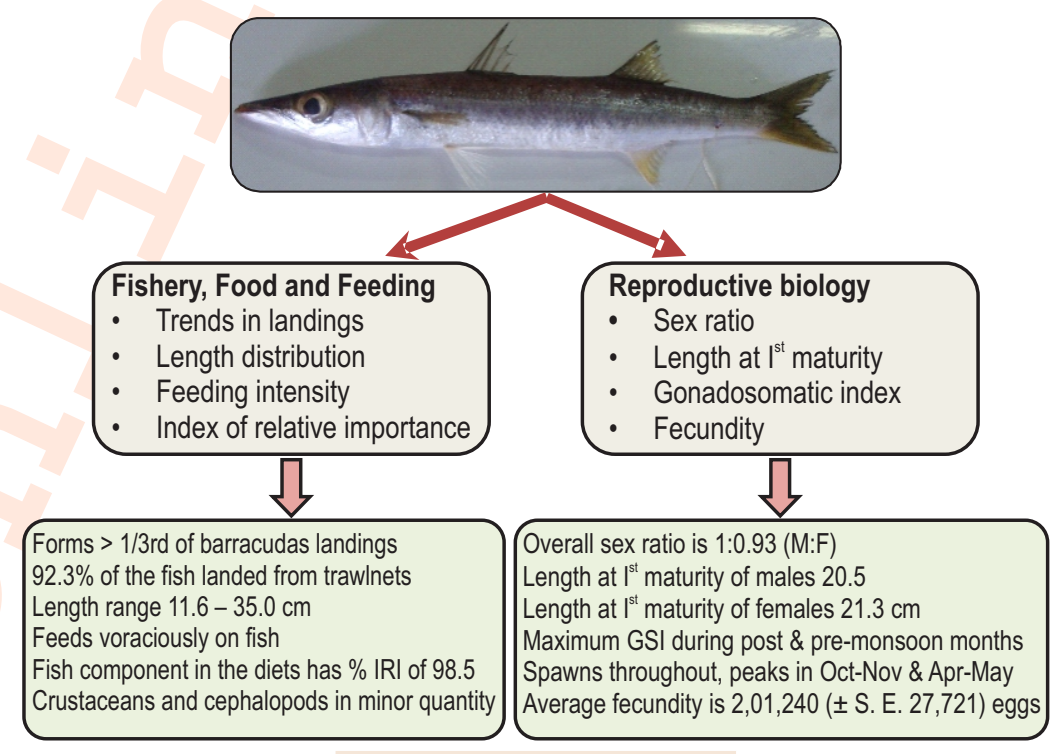

The study provides an in depth understanding of various aspects of fishery and biological aspects of obtuse barracuda, Sphyraena obtusata with respect to its length distribution, exploitation pattern, diet composition, maturity, gonadal development, fecundity and spawning season.

How to cite : Rajesh, K.M., P. Rohit and E.M. Abdussamad: Fishery and biological traits of obtuse barracuda Sphyraena obtusata (Cuvier, 1829) off south-west coast of India. J. Environ. Biol., 42, 112-117 (2021). 


\section{Introduction}

Fishes belonging to family Sphyraenidae consists of voracious predators, are economically important and widely distributed in all equatorial, tropical and warm temperate seas (Allam et al., 2004; Akadje et al., 2013). These fishes are mostly pelagic, live solitary or in schools and are capable of adaptation to diverse ecological condition (Whitehead et al., 1986). Family Sphyraenidae comonly known as barracudas include only one genus, Sphyraena and with 27 valid species globally (Froese and Pauly, 2019). Of these, only 9 species have been confirmed in India (Eschmeyer and Fong, 2017). The obtuse barracuda is a small and commercially important species of barracuda reported along the Indian coast, and is usually found in bays, estuaries (Senou, 2001), rocky areas and sea grass beds (May and Maxwell, 1986). These fishes are exploited by various fishing gears and mainly caught in trawlnets, gillnets and outboard ringseines (Senou, 2001; Najmudeen et al., 2015).

Diet composition of fish is essential to understand the basic functioning of fish assemblages and is generally used for trophic modeling as it is an important component in ecological based management (Mohanraj and Prabhu, 2012). Information on reproductive biology is an essential component in the study of the population dynamics and biology of fish species (Murua and Saborido-Rey, 2003). Numerous studies have been conducted on the fishery, length weight relationship and population dynamics of obtuse barracuda from different parts of the world (Sivashanthini et al., 2009; Kasim, 2000; Najmudeen et al., 2015). However, there is no detailed information available on feeding and reproductive biology of obtuse barracuda. Therefore, the present study was conducted to investigate the diet composition and reproductive biology of obtuse barracuda which facilitate in formulating regulatory management measures for judicious exploitation of this important fish species to maintain the fishery at sustainable levels.

\section{Materials and Methods}

Landings of $S$. obtusata by various commercial fishing vessels along Karnataka coast were gathered from the National Marine Fisheries Data Centre (NMFDC) of ICAR-Central Marine Fisheries Research Institute (ICAR-CMFRI), Kochi during the period from 2013 to 2017. Fish samples were collected on a weekly basis from Mangalore and Malpe fishing harbours of Karnataka during January 2013 to December 2017 for biological investigations. The samples were collected all round the year, except during June and July since operation of mechanized fishing vessels is prohibited. Fork length and weight of 638 male and 591 female fishes were measured to the nearest $0.1 \mathrm{~cm}$ and $0.1 \mathrm{~g}$ with a measuring tape and digital weighing balance respectively.

Feeding and reproductive traits were studied based on the analysis made on 1229 fishes. After careful dissection, stomachs and gonads taken out from the individual fishes were preserved for more detailed analyses. Based on the visual observations, fullness of stomach was classified as: empty, trace, one-fourth full, half full, three-fourth full and full. Total weight of the content in the stomachs was recorded and prey items were broadly categorized into fishes, crustaceans and cephalopods and weight of each prey item was recorded separately. Ranking was given to the various food items found in the stomach using points method. The prey items present in the stomach were identified up to the generic/species level, following the keys and identifying descriptions given by Froese and Pauly (2017) and the number of identified food items counted. Partially digested fish remains were grouped as unidentified fish remains. The index of relative importance (IRI) was determined for each diet component in the stomach (Pinkas et al., 1971) on the basis of three indices: (i) wet weight percentage of each food item (\%W) to the total weight of all the food items in the gut; (ii) percentage of the number $(\% \mathrm{~N})$ of each food item to the total number of all identified food items; and frequency of occurrence $(\% \mathrm{~F})$ of each food item in the total number of guts examined. IRI was calculated as:

$$
I R I=(\% N+\% W) \times \% F .
$$

Gonad weight was measured to the nearest $0.01 \mathrm{~g}$, maturity stages of the fishes were determined based on the macroscopic appearance of the testes or ovary and the space occupied by them in the body cavity following the method of Ferreri et al. (2009) with suitable modifications. Homogeneity in distribution of male and female and any significant deviation from the expected sex ratio of $1: 1$ was tested by Chi-square test (Snedecor and Cochran, 1967; Arshad et al., 2016). Length at first maturity $\left(L_{m}\right)$ is defined as the fork length at which $50 \%$ of the fishes reached sexual maturity was estimated following the method of King, 2007 from the logistic equation:

$$
P=1 /\left(1+\exp \left[-r \times\left(F L-L_{m}\right)\right]\right)
$$

where, $\mathrm{P}$ is the proportion of mature individuals in a length class, FL is fork length, $r$ (intercept) and $L_{m}$ (slope) are two parameters of logistic model. These two parameters were estimated using the Non-Linear Regression routine from the ratio of reproductive to non-reproductive fish groups.

Samples of ripe ovaries (maturity stage $\mathrm{V}$ and $\mathrm{VI}$ ) were preserved in $4 \%$ buffered formalin solution for estimating fecundity and ova diameter. Gonado-somatic index (GSI) was calculated considering the gonad weight and total weight of fish by the equation:

\section{GSI= [Gonad weight/ (Body weight-Gonad weight)] x 100}

Absolute fecundity was estimated by taking 3-5 subsamples from anterior, posterior and mid part of the ovary lobe as size of the egg differs from different parts. Each sub sample was weighed to the nearest $0.001 \mathrm{~g}$ and then dispensed with a fine 
brush and oocytes were counted and ova diameter measured with a grid (Murua et al., 2003). Fecundity was calculated by the formula:

$\mathrm{F}=$ [gonad weight $\mathrm{x}$ (subsample egg count / gonad sub sample weight)]

\section{Results and Discussion}

Five yearly trend (2013-2017) of Sphyraena obtusata landed in Karnataka revealed maximum and minimum landings of 2339 and 1044 t during 2015 and 2014 (Fig.1). S. obtusata (Mean value 1775 tonnes from 2013-2017) is the major species and represented more than $1 / 3^{\text {rd }}$ of the total barracuda landings (Mean value $4687 \mathrm{t}$ from 2013-2017) of the state. The contribution of $S$. obtusata to the total barracuda landings varied from 33\% (2016) to $44 \%$ (2013) during the study period (Fig. 1). The fork length of S. obtusata ranged from $11.6 \mathrm{~cm}$ to $35.0 \mathrm{~cm}$ having an estimated annual average length of $22.2 \mathrm{~cm}$. Fishes having fork length ranging between 20 and $26 \mathrm{~cm}$ dominated (84.4\%) the catch. Similar length range was reported from earlier studies (Jaiswar et al., 2004; Sivashantini et al., 2009; Najmudeen et al., 2015).

Among 1229 fishes analyzed, only 464 (37.8\%) had food component in varied quantity, while stomachs of $765(62.2 \%)$ fishes were empty. Sixty nine fishes $(5.6 \%)$ had full food content in their stomach, 39 fishes (3.2\%) with three-fourth full, 94 fishes $(7.6 \%)$ with half full, 117 fishes $(9.5 \%)$ with one-fourth full and 145 fishes $(11.8 \%)$ had trace quantity of food content in their stomach. Barracudas are generally described as specialized piscivorous (Kalogirou et al., 2012). Higher number of empty stomach is common in fishes which feed on other fishes (Juanes and Conover, 1994). In addition, the occurrence of high proportion of empty stomach could be attributed to the expulsion of food items during their struggle while they are trapped (Rajesh, et al., 2019) in trawl nets.

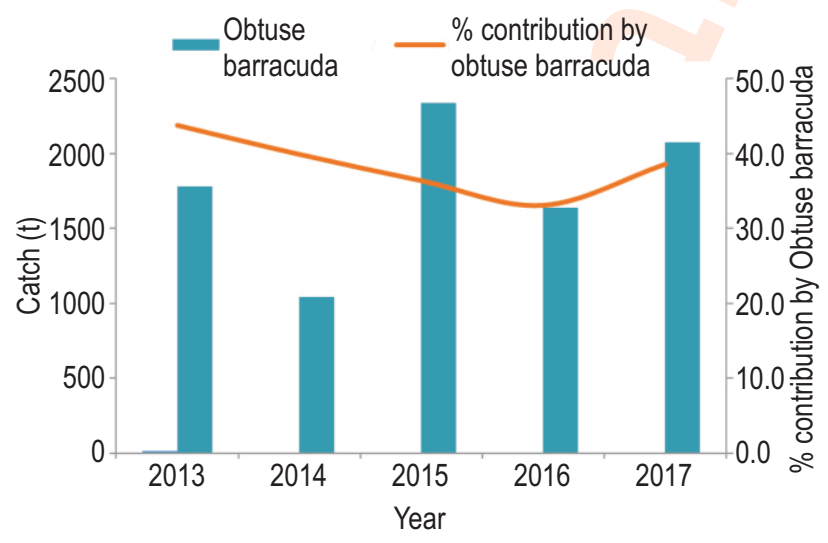

Fig. 1 : Landings (t) of obtuse barracuda and its contribution (\%) to total barracudas catch during 2013-17 in Karnataka.
The prey of obtuse barracuda belonged to three major taxonomic group viz., fishes, cephalopods and crustaceans (Table 1). Among these, the most predominant prey items in terms of frequency of occurrence (93.1\%), number (91.4\%), weight $(93.2 \%)$, and IRI $(98.5 \%)$ was fishes. The teleost group comprised of $8 \mathrm{genera} / \mathrm{species}$ and remains of partially digested fishes. Partially digested unidentified fish remains formed the largest prey item among teleosts in terms of frequency (27.3\%), number $(34.2 \%)$ weight $(30.6 \%)$ and IRI (48.3\%). These partially digested fish items could not be identified even up to family level. The identifiable teleost prey item observed in the present investigation were mostly pelagic and mesopelagic species such as Encrasicholina devisi, Bregmoceros sp., Megalaspis cordyla, Sardinella longiceps, and Leiognathus sp., except Saurida sp., a benthic teleost. Among these, the highest prey selectivity was shown towards E. devisi, Bregmoceros sp. and Megalaspis cordyla as it is evident in terms of their frequency, number, weight and IRI (Table 1). Barracudas are highly predatory in nature and feed voraciously on other pelagic and supra-benthic fishes due to their swift swimming efficiency (Kalogirou et al., 2012). Crustaceans and cephalopods represented by shrimps (unidentified) and Loligo sp., were noticed less frequently in minor quantity in the diet of $S$. obtusata (Table 1). The results of previous studies are in agreement with the present observation and reported the minor role of crustaceans and cephalopods as supplementary diet components of barracudas (Golani et al., 2006; Kalogirou et al., 2012).

Males constituted $51.9 \%(n=638)$ and females $48.1 \%$ $(n=591)$ with an overall sex ratio (males: females) of 1:0.93. In general, males dominated in almost all the months in the fishery except during April, September, November and December where more number of females was encountered. The females were dominant during few months due to migration undertaken by females for the purpose of spawning (Rajesh et al., 2016). Even though, the variations in sex ratio were observed in almost all the months, statistically significant difference were noticed only in January and October where males dominated the fishery. Detailed investigations on the reproductive biology of $S$. obtusata are not available and, hence, the result of the present study is comparable with the available literature on other species of barracudas (Allam et al., 2004). The significant dominance of females during summer season for $S$. chrysotaenia and significant predominance of males during all the season, except summer for $S$. flavicauda and the significant female dominance in autumn for $S$. sphyraena has been reported from Egyptian Mediterranean waters of Alexandria (Allam et al., 2004).

The present study is the first report on length at first maturity for both male and female fishes separately for $S$. obtusata. The estimated length at first maturity (length at which $50 \%$ of fish matured) for male and female fishes was 20.5 and 21.3 $\mathrm{cm}$, respectively. All individuals of males and females were mature 
Table 1 : Index of relative importance (IRI) of food items in the diet of $S$. obtusata

\begin{tabular}{llllll}
\hline Food components & \% Frequency & \% Number & \%Weight & $\begin{array}{l}\text { Index of relative } \\
\text { importance (IRI) }\end{array}$ & \% IRI \\
\hline Unidentified partially digested fish & 27.3 & 34.2 & 30.6 & 1771.8 & 48.3 \\
Encrasicholina devisi & 25.2 & 27.9 & 22.6 & 1271.1 & 34.6 \\
Bregmaceros sp. & 16.3 & 13.2 & 5.5 & 303.7 & 8.3 \\
Megalaspis cordyla & 8.5 & 5.4 & 10.2 & 131.7 & 3.6 \\
Decapterus sp. & 6.1 & 4.2 & 8.5 & 77.1 & 2.1 \\
Sardinella longiceps & 4.1 & 2.3 & 5.5 & 32.1 & 0.9 \\
Saurida sp. & 2.4 & 1.6 & 4.3 & 14.0 & 0.4 \\
Rastrelligerkanagurta & 1.7 & 1.4 & 3.6 & 8.7 & 0.2 \\
\hline
\end{tabular}

Table 2: Gonadosomatic index of S. obtusata

\begin{tabular}{lll}
\hline Months & Female & Male \\
\hline Jan & $3.27 \pm 0.72$ & $0.31 \pm 0.34$ \\
Feb & $6.57 \pm 0.60$ & $0.53 \pm 0.28$ \\
Mar & $10.4 \pm 1.70$ & $0.59 \pm 0.08$ \\
Apr & $19.02 \pm 2.71$ & $2.02 \pm 0.09$ \\
May & $17.72 \pm 0.73$ & $1.28 \pm 0.06$ \\
Aug & $5.27 \pm 1.89$ & $0.95 \pm 0.11$ \\
Sep & $6.34 \pm 1.95$ & $1.23 \pm 0.26$ \\
Oct & $11.53 \pm 1.77$ & $1.74 \pm 0.15$ \\
Nov & $21.38 \pm 1.10$ & $2.66 \pm 0.09$ \\
Dec & $6.98 \pm 0.76$ & $0.85 \pm 0.22$ \\
\hline
\end{tabular}

Values are mean $\pm \mathrm{SE}$.

when they attained 23.8 and $24.3 \mathrm{~cm}$ length, respectively. The results of this study suggested that male fishes mature earlier as compared to female fishes. Early maturation of males compared to females in barracudas was reported earlier for Sphyraena chrysotaenia, S. flavicauda and S. sphyraena from Egyptian Mediterranean waters (Allam et al., 2004) and for S. putnamae from south-easternArabian Sea (Rajesh et al., 2020). Further, the longer time taken by the female fishes to mature could be related to the diversion of more energy for reproduction compensating the somatic growth (Miller and Kendall, 2009; Rajesh et al., 2019).
Similar early maturation of male compared to female fishes has been reported for other species of barracudas from Egyptian Mediterranean waters of Alexandria (Allam et al., 2004). They reported the length at first maturity for males and females of $S$. chrysostaenia, S. flavicauda and S. sphyraena at 17.3 and 19.3, 25.5 and 28.0 and 26.7 and $27.6 \mathrm{~cm}$ respectively.

The mean values of gonado-somatic index (GSI) of females varied from 3.27 to 21.38 (Table 2) with the highest values observed in November (21.38), April (19.02), October (11.53) and March (10.4) signifying high reproductive activities during these months. Similar pattern of GSI was recorded in case of males with higher values in November (2.66), April (2.02), October (1.74) and May (1.28). The pattern of GSI of both females and males suggests bimodal spawning activity during OctoberNovember and April-May. Further, incidence of matured and spawning ovaries all the months in varied frequencies implied that the spawning activity takes place throughout the year. The results of the present study is in agreement with the earlier investigations carried out by Premalatha and Manojkumar (1990). They observed a prolonged spawning season from October to March with the peak period during November and December. The spawning period of other smaller barracuda species such as $S$. chrysostaenia, S. flavicauda and S. sphyraena was reported as May-July, June-July and May-June, respectively, from the Egyptian Mediterranean waters of Alexandria (Allam et al., 2004).

Table 3 : Fecundity and ova diameter in S. obtusata

\begin{tabular}{llll}
\hline Length of fish $\mathbf{( c m})$ & Weight $(\mathbf{g})$ & Fecundity $(\mathbf{n o})$. & Ova diameter $(\mathbf{m m})$ \\
\hline 25.5 & 94.7 & 82,722 & $0.04-0.73$ \\
25.8 & 98.5 & 88,128 & $0.05-0.68$ \\
26.0 & 103.1 & $1,30,752$ & $0.04-0.70$ \\
26.2 & 100.9 & $1,54,991$ & $0.08-0.78$ \\
26.6 & 106.5 & $1,96,447$ & $0.11-0.80$ \\
26.9 & 107.3 & $2,08,001$ & $0.09-0.83$ \\
28.3 & 112.5 & $2,26,653$ & $0.12-0.72$ \\
28.7 & 121.3 & $2,64,653$ & $0.14-0.76$ \\
30.1 & 148.5 & $2,80,630$ & $0.11-0.78$ \\
30.7 & 155.6 & $3,79,421$ & $0.11-0.83$ \\
\hline
\end{tabular}


The fecundity estimates from an individual female fish varied from from 82,722 to $3,79,421$ eggs (Table 3) with an average of 2,01,240. Fecundity correlated positively with fork length, body weight and gonad weight of obtuse barracuda indicating that the larger females produce more number of eggs compared to smaller ones. The absolute fecundity of 74,399 to $2,41,853,84,197$ to $2,60,549$ and 46,778 to $1,03,453$ eggs were estimated for S. chrysotaenia, S. flavicauda and S. sphyraena in the Egyptian Mediterranean waters of Alexandria (Allam et al., 2004). The fecundity of obtuse barracuda increased with length and weight in the present study is in agreement with the earlier studies conducted for other Sphyraena species (Wadie et al., 1988;Allam et al., 2004).

The ova diameter ranged from 0.04 to $0.83 \mathrm{~mm}$. Three groups such as immature, maturing and ripe eggs were noticed in the ovary of $S$. obtusata. Immature eggs were small, non-yolked and whitish translucent, maturing eggs were partially opaque with lot of yolk and ripe eggs were completely transparent. The presence of ova in different developmental stages represents that this species is a multiple spawner releasing ripe eggs in various fractions in batches during spawning period (Allam et al., 2004).

The result of this study provides some important aspects of fishery, food and feeding habits and reproductive biology of $S$. obtusata along the south-west coast of India. This comprehensive information on major biological characteristics could be useful for developing appropriate management strategies for conservation and judicious exploitation of this commercially important fish species to maintain the fishery at sustainable levels.

\section{Acknowledgment}

The authors convey their profound gratitude and heartfelt thanks to the Director, ICAR-CMFRI, Kochi for his constant encouragement and facilities provided for taking up this study.

\section{Add-on Information}

Authors' contribution: K. M. Rajesh: Collection of Data, Experimental design, writing and editing of the paper; P. Rohit: Experimental design, writing and editing the paper; E. M. Abdussamad: Writing and editing of the paper.

Research content: The research contents is original and has not been published elsewhere

Ethical approval: NotApplicable.

Conflict of interest: The author declares that there is no conflict of interest.

\section{Data from other sources: NotApplicable}

Consent to publish: All authors agree to publish the paper in Journal of Environmental Biology.

\section{References}

Akadje, C., M. Diaby, F. Le Loc'h, J.K. Konan and K. N'da: Diet of the barracuda Sphyraena guachancho in Côte d'Ivoire (Equatorial Eastern Atlantic Ocean). Cybium, 37, 285-293 (2013).

Allam, S.M., S.N. Faltas and E. Ragheb: Reproductive biology of Sphyraena species in the Egyptian Mediterranean waters of Alexandria. Egyp. J. Aquat. Res., 30, 255-270 (2004).

Arshad, A., A.A. Amani, S.M. Nurulamin and F.M. Yusoff: Sex ratio, spawning season and the size at maturity of Parapenaeopsis sculptilis (Heller 1862) in the coastal waters of Perak, Peninsular Malaysia. J. Environ. Biol., 37, 709-713 (2016).

Eschmeyer, W.N. and J.D. Fong: Catalogue of fishes. http:// researcharchive.calacademy.org/research/ ichthyology/catalog/ SpeciesByFamily.asp\#Sphyraenidae. (2017).

Ferreri, R., G. Basilone, M. D'elia, A. Traina, F. Saborido-Rey and S. Mazzola: Validation of macroscopic maturity stages according to microscopic histological examination for European anchovy. Mar. Ecol., 30, 181-187 (2009).

Froese, R. and D. Pauly: Fish Base. World Wide Web Electronic Publication. http://www.fishbase.org (2017).

Froese, R. and D. Pauly: Fish Base Version (04/2019). World Wide Web Electronic Publication, www.fishbase.org (2019).

Golani, D., B. Ozturk and N. Basusta: Fishes of the Eastern Mediterranean. Istanbul:Turkish Marine Research Foundation. Publication No. 24, Istanbul, Turkey, pp. 259 (2006).

Jaiswar, A.K., P.K. Parida, S.K. Chakraborty and R. Palaniswamy: Morphometry and length-weight relationship of obtuse barracuda Sphyraena obtusata (Cuvier) (Teleostomi/ Actinopterygii/ Sphyraenidae) from Bombay waters, west coast of India. Indian J. Mar. Sci., 33, 307-309 (2004).

Juanes, F. and D.O. Conover: Rapid growth, high feeding rates and early piscivory in young of the year blue fish (Pomatomus saltatrix). Can. J. Fish. Aquat. Sci., 51, 1752-1761 (1994).

Kalogirou, S., F. Mittermayer, L. Pihl and H. Wennhage: Feeding ecology of indigenous and non-indigenous fish species within the family Sphyraenidae. J. Fish Biol., 80, 2528-2548 (2012).

Kasim, H.M.: Fishery, stock assessment and management of the barracuda resource in India. In: Fisheries Research and Management (Eds.: V.N. Pillai and N.G. Menon). Central Marine Fisheries Research Institute, Cochin, pp. 914 (2000).

King, M.: Fisheries Biology, Assessment and Management. $2^{\text {nd }}$ Edn., Blackwell Publishing Ltd. (2007).

May, J.L. and J.G.H. Maxwell: Trawl fish from temperate waters of Australia. CSIRO Division of Fisheries Research, Tasmania, pp. 492 (1986).

Miller, B. and A.W. Kendall: Early life histories of marine fishes. $1^{\text {st }}$ Edn., University of California Press. pp. 376 (2009).

Mohanraj, T. and K. Prabhu: food habits and diet composition of demersal marine fishes from Gulf of Mannar, Southeast Coast of India. Adv. Biol. Res., 6,159-164 (2012).

Murua, H. and F. Saborido-Rey: Female reproductive strategies of marine fish species of the north Atlantic. J. Northw. Atl. Fish. Sci., 33, 23-31 (2003)

Murua, H., G. Kraus, F. Saborido-Roy, P.R. Witthames, A. Thorsen and S. Junquera: Procedures to estimate fecundity of marine fish species in relation to their reproductive strategy. J. Northw. Atl. Fish. Sci., 33, 33-54 (2003).

Najmudeen, T.M., P.K. Seetha and P.U. Zacharia: Fishery and population dynamics of the obtuse barracuda Sphyraena obtusata (Cuvier) 
landed by trawlers at Cochin, South-west coast of India. Indian J. Fish., 62, 14-18(2015).

Pinkas, L., M.S. Oliphant and I.L.K. Iverson: Food habits of albacore, bluefin tuna and bonito in Californian waters. Calif. Dep. Fish. Game Fish. Bull., 152, 1-105 (1971).

Premalatha, P. and P.P. Manojkumar: Some biological aspects of two species of Barracudas from the South West coast of India. Indian J. Fish., 37, 289-295 (1990).

Rajesh, K. M., P. Rohit and E.M. Abdussamad: Fishery, diet composition and reproductive biology of the dolphinfish Coryphaena hippurus (Linnaeus, 1758) off Karnataka, South-west coast of India. Indian J. Fish., 63, 35-40 (2016).

Rajesh, K. M., P. Rohit, K. G. Mini, T. Sathyavathi and A. M. Hakeem: Seriolina nigrofasciata (Ruppel, 1829), its fishery and biological aspects off south-west coast of India (Bloch, 1790). Indian J. Fish., 66, 9-16 (2019).

Rajesh, K. M., P. Rohit, E.M. Abdussamad and D. Viswambharan: Reproductive biology of the sawtooth barracuda, Sphyraena putnamae (Jordan and Seale, 1905) along the coastal waters of
Karnataka, southeastern Arabian Sea. Reg. Stud. Mar. Sci., 36 (2020). https://doi.org/10.1016/j.rsma.2020.101314.

Senou, H.: Sphyraenidae. Barracudas. In: The Living Marine Resources of the Western Central Pacific (Eds.: K.E. Carpenter and V. Niem). FAO Species Identification Guide for Fishery Purposes. Vol. 6. FAO, Rome, pp. 3685-3697 (2001).

Sivashanthini, K., G. Gayathri and K. Gajapathy: Length-weight relationship of Sphyraena obtusata Cuvier 1829 (Pisces: Perciformes) from the Jaffna Lagoon, Srilanka. J. Fish. Aquat. Sci., 4, 111-116 (2009).

Snedecor, G.W. and W.G. Cochran: Statistical Methods. $6^{\text {th }}$ Edn., Oxford and IBH Publishing Co., New Delhi, 593 (1967).

Wadie, W.F., S.I. Rizkalla and N.M. Dowidar: Maturity in the Sphyraenidae family in the south-eastern Mediterranean. Folia Morphol, 36, 365-380 (1988).

Whitehead, P.J.P., M.L. Bauchot, J.C. Hureau, J. Nielsen and E. Tortonese: Fishes of the North-Eastern Atlantic and Mediterranean. The Quarterly Rev. Biol., 61, 1473 (1986). 